\title{
Model Routing Data pada Pembangkit Listrik Tenaga Mikrohidro (PLTMH) Berbasis Jaringan Sensor Nikabel (JSN)
}

\section{Data Routing Model of Micro Hydro Power Plant (MHPP) Based on Wireless Sensor Network (WSN)}

\author{
Nivika Tiffany Somantri ${ }^{1 *}$, Naftalin Winanti ${ }^{2}$, Fatkhurrohman ${ }^{3}$ \\ ${ }^{1,2}$ Universitas Jenderal Achmad Yani \\ Jl. Terusan Jenderal Sudirman PO BOX 148 Cimahi, Telp (022) 6642063 \\ ${ }^{3}$ PT. Indofood CBP Sukses Makmur Tbk. \\ Jalan Raya Caringin No 353 Kertajaya Padalarang Bandung Barat, Telp (022) 6809813 \\ nivika.tiffany@lecture.unjani.ac.id ${ }^{1 *}$, naftalin.winanti@lecture.unjani.ac.id ${ }^{2}$, \\ fatkhurrohman@icbp.indofood.co.id ${ }^{3}$
}

\begin{abstract}
Abstrak - Pembangkit listrik tenaga mikrohidro adalah salah satu sumber energi listrik terbarukan saat ini dengan memanfaatkan tenaga air berskala kecil untuk penggeraknya. PLTMH pada umumnya memiliki ruang kontrol yang berada jauh dengan sistemnya, sehingga dibutuhkan suatu sistem monitoring. Penggunaan sistem monitoring berbasis nirkabel menjadi salah satu solusi untuk mengatasi masalah tersebut dengan proses pengiriman informasi yang cepat dan mudah. Penelitian ini merancang suatu model routing data dengan perancangan hardware dan software pada komunikasi data. Sistem dibangun menggunakan mikrokontroller arduino dan komunikasi frekuensi Xbee dengan protocol zigbee. Pengujian dilakukan dengan menggunakan berbagai macam topologi yaitu topologi pair, star, mesh, tree, dan $x$ dalam model routing data baik dalam lingkungan indoor maupun lingkungan outdoor. Hasil yang didapat berdasarkan pengujian pada lingkungan indoor menunjukan Xbee tetap dapat mengirim dalam ruangan yang memiliki penghalang dengan jarak $21 \mathrm{~m}$, sedangkan pada pengujian outdoor, Xbee dapat tetap mengirim dengan jarak maksimum 120.5 m menggunakan model topologi $x$. Berdasarkan semua pemodelan yang telah dilakukan, topologi $x$ merupakan model yang dianggap paling berhasil walaupun memiliki kelemahan dalam tingkat kerapihan penerimaan data namun dari tingkat keamanannya ketika terjadi masalah dengan salah satu node, topologi x masih memiliki jalur lain untuk dapat mengirimkan data ke penerima.
\end{abstract}

Kata Kunci: Model perutean data, JSN, PLTMH, topologi, Xbee.

\begin{abstract}
Micro hydropower plant is one of the current renewable electrical energy by making use of small-scale water power for propulsion. MHPP generally has a control room that was away with the system, so we need a monitoring system. The use of wireless-based monitoring systems into one solution to overcome these problems with the delivery process information quickly and easily. Therefore, we designed a model of routing data by designing hardware and software in data communication comprising Arduino microcontroller and Xbee frequency communication with ZigBee protocol. Testing is done by using a variety of topologies, namely topology pair, star, mesh, tree, and $x$ in the model routing of data in both the indoor and outdoor environment. The results obtained by testing the indoor environment is Xbee can still
\end{abstract}

TELKA, Vol.7, No.1, Mei 2021, pp. 49 61

ISSN (e): 2540-9123 
send in a room that had a barrier at a distance of $21 \mathrm{~m}$, while the outdoor testing Xbee can still send more than the maximum distance delivery Xbee $70.5 \mathrm{~m}$ in research that is by using the model topology $x$. Based on all the modeling that has been done, topology $x$ is the model that is considered the most successful even though it has weaknesses in the level of data reception tidiness. But the level of security has the advantage that when there is a problem with one of the nodes, the xtopology still has another path to be able to send data to the receiver.

Keywords: Data routing model, WSN, MHPP, topology, Xbee.

\section{Pendahuluan}

Sebuah sistem monitoring melakukan proses pengumpulan data dimana data yang dikumpulkan pada umumnya merupakan data yang real-time [1]. Waktu didalam pengertian tersebut berarti bahwa sistem yang real-time menjalankan suatu pekerjaan yang memiliki batas waktu (deadline) [2].

Sistem monitoring itu sendiri dapat di aplikasikan untuk proses dalam monitoring Pembangkit Listrik Tenaga Mikro Hidro (PLTMH). Dalam sistem monitoring Pembangkit Listrik Tenaga Mikro Hidro, penggunaan jaringan sensor nirkabel dapat memonitoring dan mengontrol sistem dengan menghemat waktu dan biaya seperti pengolahan pada data akuisisinya dan pengolahan pada efisiensi jalur yang dilewati oleh informasinya [3]. Dengan sistem monitoring yang ada pada PLTMH kita dapat mengetahui sistem bekerja dengan baik atau tidak dan apabila terjadi gangguan pada sistem PLTMH maka pada sistem monitoring akan terdeteksi dengan cepat sehingga respon penangannya akan lebih cepat [4].

PLTMH yang ada saat ini berada di lingkungan terbuka sehingga dalam pengontrolannya memerlukan suatu sistem monitoring yang akan mempermudah proses pengontrolan pada sistem di PLTMH itu sendiri[5]. Sistem monitoring adalah suatu sistem dengan menggunakan media kabel maupun wireless dalam penyampaian informasinya. Dalam sistem monitoring, memerlukan suatu topologi yang cocok dalam proses pengiriman datanya. Topologi yang biasa dikenal seperti topologi pair, star, mesh, tree biasa digunakan dalam proses pengiriman data [6].

Pada penelitian dilakukan sebuah sistem monitoring menggunakan jaringan sensor nirkabel. Jaringan sensor nirkabel merupakan jaringan yang terdiri dari kumpulan node sensor yang tersebar di suatu area tertentu, tiap node memiliki kemampuan untuk pengiriman data yang diantara proses tersebut terdapat banyak node sensor [7]. Pada proses pengiriman data akan dilakukan pemilihan model routing data agar data yang dikirimkan dapat sesuai dengan jalur pengiriman yang telah disediakan. Jaringan sensor nirkabel yang digunakan dalam penelitian ini berbasis Arduino dan Xbee, dimana dengan menggunakan Arduino dan Xbee diharapkan dapat mengirim data lebih dari $30 \mathrm{~m}$ [8] dan dengan menggunakan jaringan sensor nirkabel berbasis Arduino dan xbee juga memiliki keuntungan yaitu dapat digunakan di lingkungan indoor maupun outdoor tanpa gangguan cuaca. Tak hanya itu, sifat open source arduino juga banyak memberikan keuntungan tersendiri ketika menggunakan board ini, karena dengan sifat open source komponen yang akan dipakai tidak hanya tergantung pada satu merek, namun memungkinkan kita bisa memakai semua komponen yang ada dipasaran [9].

\section{Metode Penelitian}

Pada penelitian ini dilakukan perancangan suatu model routing data dalam sistem monitoring tegangan dan optocoupler pada pembangkit listrik tenaga mikrohidro secara nirkabel berbasis Arduino IDE dengan komunikasi data menggunakan perangkat Xbee. Sistem nantinya akan diterapkan untuk proses pengiriman data yang didapat dari keluaran sensor optocoupler dan sensor tegangan yang ada di pembangkit listrik tenaga mikrohidro. Perancangan sistem sendiri di bagi menjadi dua bagian yaitu, perancangan software dan perancangan hardware. 


\subsection{Perancangan Software}

Perancangan software dilakukan pada program $X$-CTU dan Arduino IDE. Pada software $X$ $C T U$, Xbee di setting terlebih dahulu untuk dijadikan sebagai end device, router dan coordinator lalu setelah di setting maka diupdate the radio firmware library untuk tahap akhir. Sedangkan software Arduino IDE digunakan untuk program sensor tegangan, sensor optocoupler dan penerima , kemudian di-download ke mikrokontroler Arduino. Untuk men-download source code tersebut dibutuhkan kabel USB untuk menghubungkan rangkaian penerima secara serial ke computer. Diagram alir untuk perancangan software ditunjukkan pada Gambar 1.

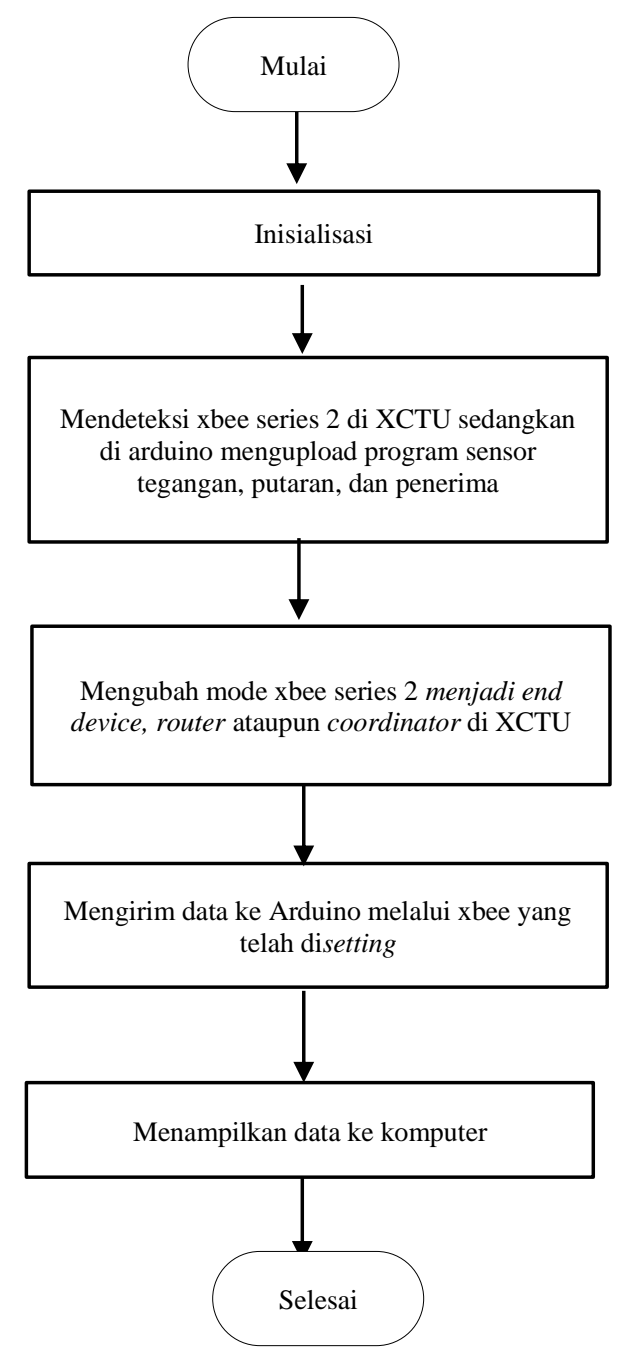

Gambar 1. Diagram alir perancangan software.

Pada gambar diagram alir diatas dapat dijelaskan ketika alat dijalankan, mikrokontroler akan melalukan inisialisasi seluruh port terlebih dahulu. Proses berikutnya mendeteksi Xbee series 2 di software XCTU sedangkan pada arduino pemograman sensor tegangan dan optocoupler di upload lalu mengubah terlebih dahulu mode pada Xbee series 2 agar data yang ada pada arduino dapat dikirim melalui Xbee yang telah dikonfigurasikan.

\subsection{Perancangan Hardware}

Pada perancangan hardware ini terdiri dari rangkaian pengirim, perantara dan rangkaian penerima. Rangkaian pengirim terdiri dari beberapa rangkaian, yakni rangkaian sensor tegangan 
dan sensor optocoupler. Gambar rangkaian pada perancangan hardware dapat dilihat pada Gambar 2-6.

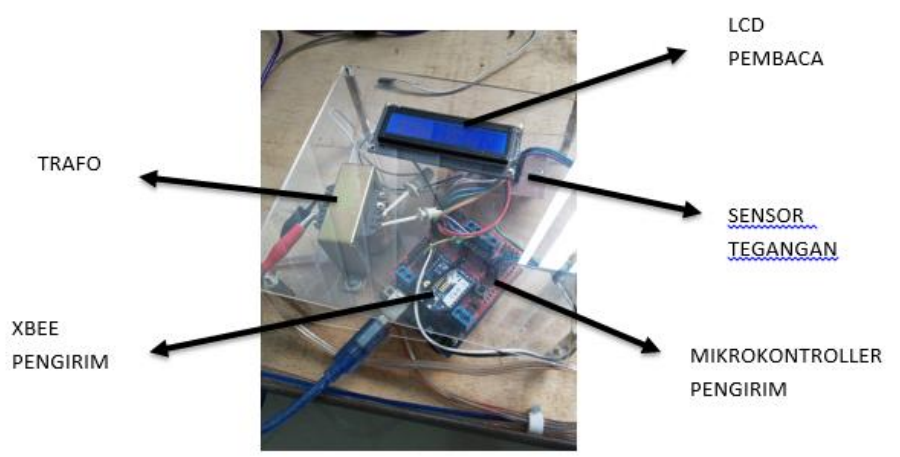

Gambar 2. Rangkaian pengirim sensor tegangan.

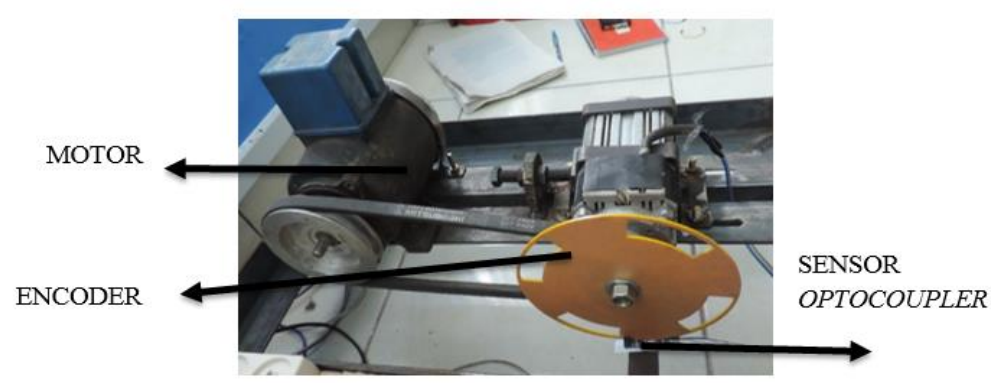

Gambar 3. Rangkaian sensor optocoupler.

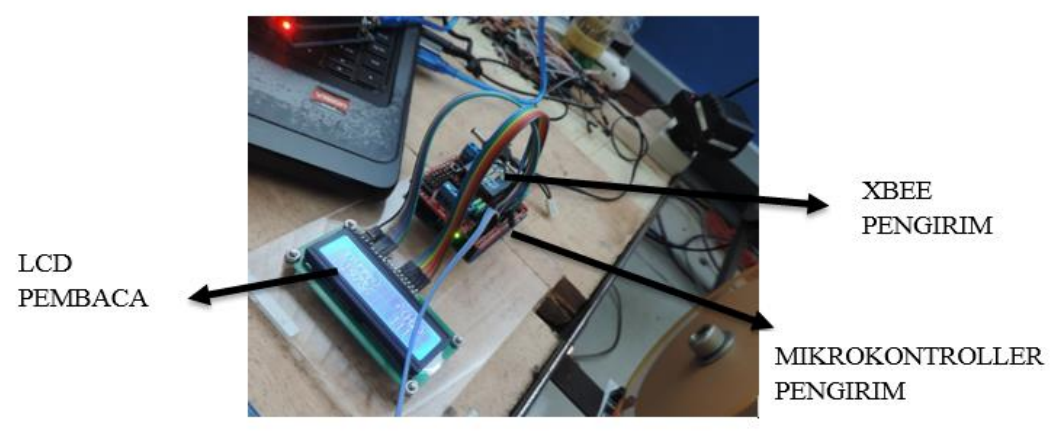

Gambar 4. Rangkaian mikrokontroller pengirim.

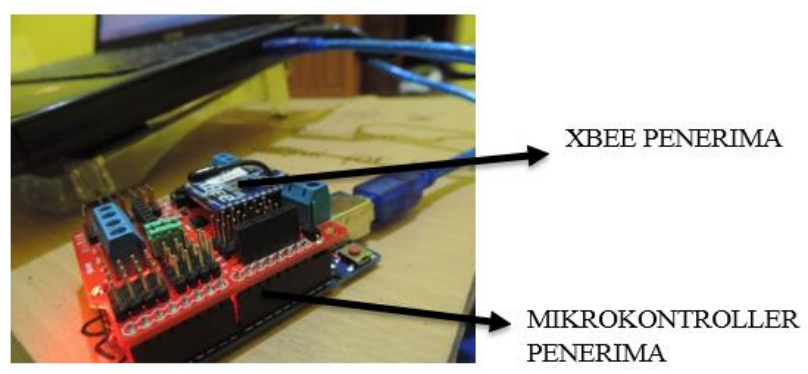

Gambar 5. Rangkaian mikrokontroller penerima. 


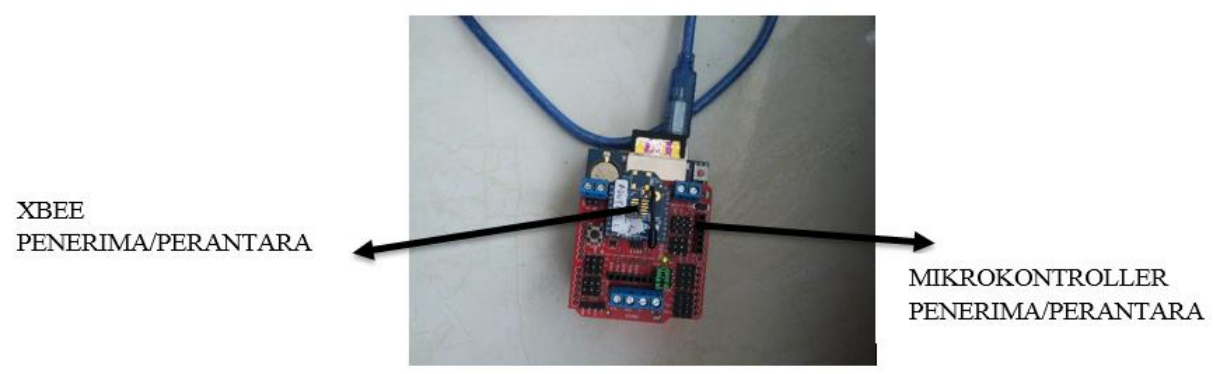

Gambar 6. Rangkaian mikrokontroller perantara.

\subsection{Perancangan Topologi}

Perancangan topologi berfungsi untuk mengatur xbee sesuai dengan topologi yang akan digunakan. Perancangan ini menggunakan topologi pair, star, mesh, tree 1, tree 2 dan topologi $\mathrm{x}$. Topologi yang digunakan adalah topologi yang dapat diaplikasikan oleh Xbee series 2, sedangkan topologi $\mathrm{x}$ adalah topologi yang dirancang dengan menggabungkan beberapa topologi yang ada.

\section{a. Topologi Pair}

Topologi pair menggunakan 2 Xbee yang saling berkomunikasi. Xbee tersebut difungsikan sebagai end device dan coordinator. Topologi pair dapat dilihat pada Gambar 7.

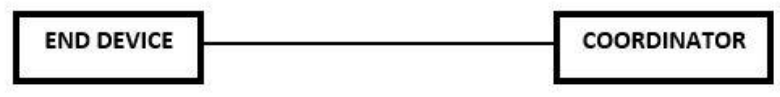

Gambar 7. Topologi pair.

\section{b. Topologi Star}

Topologi star menggunakan 3 Xbee dengan 2 Xbee sebagai pengirim dan 1 Xbee sebagai penerima, seperti pada Gambar 8 yang menunjukkan topologi star.

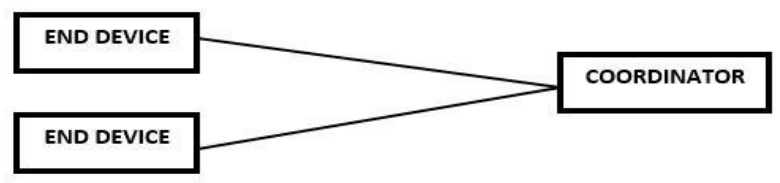

Gambar 8. Topologi star.

c. Topologi Mesh

Topologi Mesh menggunakan 3 Xbee sebagai end device, router dan coordinator. Topologi mesh dapat dilihat pada Gambar 9.

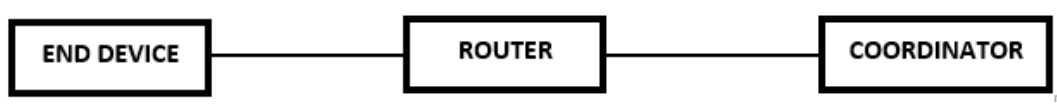

Gambar 9. Topologi mesh.

\section{d. Topologi Tree 1}

Topologi tree 1 memanfaatkan 5 Xbee. Xbee-Xbee tersebut difungsikan sebagai end device (pengirim), 2 router (perantara), 1 router (penerima) dan 1 coordinator (penerima). Gambar 10 menunjukkan topologi tree 1. 


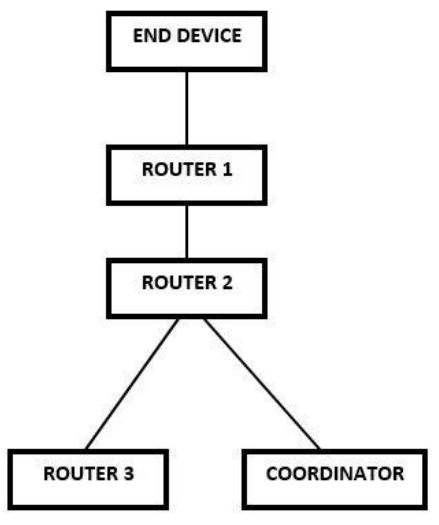

Gambar 10. Topologi tree 1.

e. Topologi Tree 2

Sama seperti topologi tree 1 , tree 2 menggunakan 5 Xbee yang berfungsi sebagai end device (pengirim) dengan jumlah 2 buah, router 1 (perantara) dengan jumlah 1 buah, router 2 dan router 3 (penerima) dan 1 coordinator. Gambar 11 menunjukkan topologi tree 2.

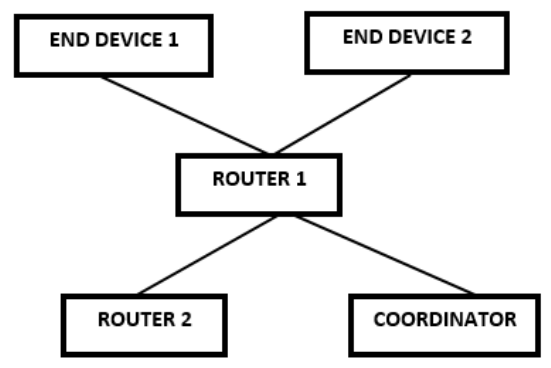

Gambar 11. Topolgi tree 2.

\section{f. Topologi X}

Pemodelan topologi $\mathrm{x}$ ini memiliki 2 router yang fungsinya sebagai perantara antara end device dan coordinator. Oleh karena itu, end device tidak dapat mengirim data menuju coordinator apabila router 1 ataupun router 2 dimatikan. Topologi $\mathrm{x}$ dapat terlihat pada Gambar 12.

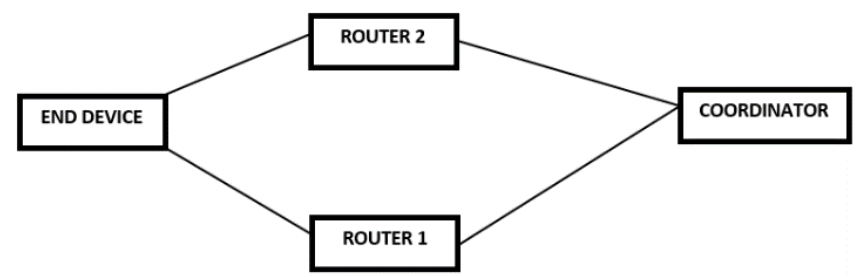

Gambar 12. Topologi x.

\section{Hasil dan Pembahasan}

Setelah sistem selesai dirancang, Pengujian ini bertujuan menguji setiap topologi untuk mengetahui kinerja dari masing-masing topologi serta melakukan pengecekan apakah topologi tersebut telah bekerja sesuai dengan fungsinya. Pengujian yang dilakukan ada 2 yaitu pengujian indoor dan pengujian outdoor. 
Secara umum perancangan suatu model routing data dalam sistem monitoring tegangan dan optocoupler pada pembangkit listrik tenaga mikrohidro secara nirkabel berbasis Arduino IDE dengan komunikasi data menggunakan perangkat xbee telah berfungsi dengan baik dengan pengujian dimodelkan oleh topologi pair, topologi star, topologi mesh, topologi tree, dan topologi $\mathrm{x}$.

Dengan melihat hasil dari berbagai pemodelan, modul Xbee berfungsi cukup baik, hal ini ditunjukkan pada pengujian indoor dan outdoor. Pada pengujian indoor data terkirim dari ruang 1 hingga ruang 5 atau berjarak 21 meter. Pengujian tersebut dikatakan cukup baik karena keterbatasan modul Xbee yang memiliki daya rendah sehingga untuk menembus berbagai dinding memiliki kesulitan. Sedangkan pada lingkungan outdoor, modul Xbee berfungsi cukup baik karena pengujian outdoor Xbee dapat mengirim data hingga lebih $100 \mathrm{~m}$. Hal ini sesuai dengan spesifikasi dari modul tersebut[]. Pengujian dilakukan dengan tanpa adanya penghalang (line of sight). Sehingga modul Xbee ini dapat bekerja baik untuk proses monitoring.

a. Topologi Pair

Topologi pair menggunakan 2 Xbee yang saling berkomunikasi. Xbee tersebut difungsikan sebagai end device dan coordinator. Hasil pengujian untuk topologi pair dapat dilihat pada Tabel 1.

Tabel 1. Pengujian topologi pair.

\begin{tabular}{cc}
\hline Kondisi End Device & Kondisi Coordinator \\
\hline Mengirim Data & Menerima Data \\
Mati & Tidak Menerima Data \\
\hline
\end{tabular}

b. Topologi Star

Topologi star menggunakan 3 Xbee dengan 2 Xbee sebagai pengirim dan 1 Xbee sebagai penerima, seperti pada Tabel 2 yang menunjukkan hasil pengujian untuk topologi star.

Tabel 2. Pengujian topologi star.

\begin{tabular}{ccc}
\hline Kondisi End Device 1 & Kondisi End Device 2 & Kondisi Coordinator \\
\hline Mengirim Data & Mengirim Data & Menerima Data Dari Kedua End Device \\
Mati & Mengirim Data & Menerima Data End Device 2 \\
Mengirim Data & Mati & Menerima Data End Device 1 \\
\hline
\end{tabular}

c. Topologi Mesh

Topologi Mesh menggunakan 3 Xbee sebagai end device, router dan coordinator. Hasil pengujian untuk topologi mesh dapat dilihat pada Tabel 3.

Tabel 3. Pengujian topologi mesh.

\begin{tabular}{ccc}
\hline Kondisi End Device & Kondisi Router & Kondisi Coordinator \\
\hline Mengirim Data & Menyampaikan Data & Menerima Data \\
Mati & Tidak Menyampaikan & Tidak Menerima Data \\
Mengirim Data & Data & Tidak Menerima Data \\
\hline
\end{tabular}

\section{d. Topologi Tree 1}

Topologi tree 1 memanfaatkan 5 Xbee. Xbee-Xbee tersebut difungsikan sebagai end device (pengirim), 2 router (perantara), 1 router (penerima) dan 1 coordinator (penerima). Tabel 4 menunjukkan hasil pengujian untuk topologi tree 1. 
Tabel 4. Pengujian topologi tree 1.

\begin{tabular}{|c|c|c|c|c|}
\hline $\begin{array}{l}\text { Kondisi End } \\
\text { Device }\end{array}$ & Kondisi Router 1 & Kondisi Router 2 & Kondisi Router 3 & $\begin{array}{c}\text { Kondisi } \\
\text { Coordinator }\end{array}$ \\
\hline Mengirim Data & $\begin{array}{l}\text { Menyampaikan } \\
\text { Data }\end{array}$ & $\begin{array}{l}\text { Menyampaikan } \\
\text { Data }\end{array}$ & Menerima Data & Menerima Data \\
\hline Mati & $\begin{array}{c}\text { Tidak } \\
\text { Menyampaikan } \\
\text { Data }\end{array}$ & $\begin{array}{c}\text { Tidak } \\
\text { Menyampaikan } \\
\text { Data }\end{array}$ & $\begin{array}{c}\text { Tidak Menerima } \\
\text { Data }\end{array}$ & $\begin{array}{c}\text { Tidak Menerima } \\
\text { Data }\end{array}$ \\
\hline Mengirim Data & Mati & $\begin{array}{c}\text { Tidak } \\
\text { Menyampaikan } \\
\text { Data }\end{array}$ & $\begin{array}{c}\text { Tidak Menerima } \\
\text { Data }\end{array}$ & $\begin{array}{c}\text { Tidak Menerima } \\
\text { Data }\end{array}$ \\
\hline Mengirim Data & $\begin{array}{l}\text { Menyampaikan } \\
\text { Data }\end{array}$ & Mati & $\begin{array}{c}\text { Tidak Menerima } \\
\text { Data }\end{array}$ & $\begin{array}{c}\text { Tidak Menerima } \\
\text { Data }\end{array}$ \\
\hline Mengirim Data & $\begin{array}{c}\text { Menyampaikan } \\
\text { Data }\end{array}$ & $\begin{array}{l}\text { Menyampaikan } \\
\text { Data }\end{array}$ & Mati & Menerima Data \\
\hline Mengirim Data & $\begin{array}{c}\text { Menyampaikan } \\
\text { Data }\end{array}$ & $\begin{array}{l}\text { Menyampaikan } \\
\text { Data }\end{array}$ & Menerima Data & Mati \\
\hline
\end{tabular}

\section{e. Topologi Tree 2}

Sama seperti topologi tree 1, tree 2 menggunakan 5 Xbee yang berfungsi sebagai end device (pengirim) dengan jumlah 2 buah, router 1 (perantara) dengan jumlah 1 buah, router 2 dan router 3 (penerima) dan 1 coordinator. Tabel 5 menunjukkan hasil pengujian untuk topologi tree 2 .

Tabel 5. Pengujian topologi tree 2.

\begin{tabular}{|c|c|c|c|c|}
\hline $\begin{array}{l}\text { Kondisi End } \\
\text { Device } 1\end{array}$ & $\begin{array}{l}\text { Kondisi End } \\
\text { Device } 2\end{array}$ & Kondisi Router 1 & $\begin{array}{c}\text { Kondisi Router } \\
2\end{array}$ & $\begin{array}{c}\text { Kondisi } \\
\text { Coordinator }\end{array}$ \\
\hline $\begin{array}{l}\text { Mengirim } \\
\text { Data }\end{array}$ & $\begin{array}{l}\text { Mengirim } \\
\text { Data }\end{array}$ & $\begin{array}{c}\text { Menyampaikan } \\
\text { Data }\end{array}$ & Menerima Data & Menerima Data \\
\hline Mati & $\begin{array}{l}\text { Mengirim } \\
\text { Data }\end{array}$ & $\begin{array}{c}\text { Menyampaikan } \\
\text { Data End Device } \\
2\end{array}$ & $\begin{array}{l}\text { Menerima Data } \\
\text { End Device } 2\end{array}$ & $\begin{array}{l}\text { Menerima Data } \\
\text { End Device } 2\end{array}$ \\
\hline $\begin{array}{l}\text { Mengirim } \\
\text { Data }\end{array}$ & Mati & $\begin{array}{c}\text { Menyampaikan } \\
\text { Data End Device } \\
1\end{array}$ & $\begin{array}{l}\text { Menerima Data } \\
\text { End Device } 1\end{array}$ & $\begin{array}{l}\text { Menerima Data } \\
\text { End Device } 1\end{array}$ \\
\hline $\begin{array}{l}\text { Mengirim } \\
\text { Data }\end{array}$ & $\begin{array}{l}\text { Mengirim } \\
\text { Data }\end{array}$ & Mati & $\begin{array}{c}\text { Tidak } \\
\text { Menerima Data }\end{array}$ & $\begin{array}{c}\text { Tidak } \\
\text { Menerima Data }\end{array}$ \\
\hline $\begin{array}{l}\text { Mengirim } \\
\text { Data }\end{array}$ & $\begin{array}{l}\text { Mengirim } \\
\text { Data }\end{array}$ & $\begin{array}{c}\text { Menyampaikan } \\
\text { Data }\end{array}$ & Mati & Menerima Data \\
\hline $\begin{array}{l}\text { Mengirim } \\
\text { Data }\end{array}$ & $\begin{array}{l}\text { Mengirim } \\
\text { Data }\end{array}$ & $\begin{array}{c}\text { Menyampaikan } \\
\text { Data }\end{array}$ & Menerima Data & Mati \\
\hline
\end{tabular}

\section{f. Topologi X}

Pemodelan topologi $\mathrm{x}$ ini memiliki 2 router yang fungsinya sebagai perantara antara end device dan coordinator. Oleh karena itu, end device tidak dapat mengirim data menuju coordinator apabila router 1 ataupun router 2 dimatikan. Hasil pengujian untuk topologi $\mathrm{x}$ dapat terlihat pada Tabel 6 . 
Tabel 6. Pengujian topologi $\mathrm{x}$.

\begin{tabular}{cccc}
\hline Kondisi End & Kondisi Router 1 & Kondisi Router 2 & Kondisi Coordinator \\
\hline Mengirim Data & Menyampaikan & Menyampaikan & Menerima Data \\
& Data & Data & \\
Mati & Tidak & Tidak & Tidak Menerima Data \\
& Menyimpaikan Data & $\begin{array}{c}\text { Menyampaikan } \\
\text { Data }\end{array}$ & \\
Mengirim Data & Mati & Menyampaikan & Menerima Data \\
& & Data & \\
Mengirim Data & Menyampaikan & Mati & Menerima Data \\
& Data & &
\end{tabular}

Setelah melakukan proses pengecekan dengan topologi-topologi yang ada, kemudian dilakukan pengujian pemantauan secara nirkabel dengan beberapa buah Xbee sesuai dengan topologi yang digunakan. Pengujian dilakukan pada indoor dan outdoor. Skema pengujian dapat dilihat pada Gambar 13.

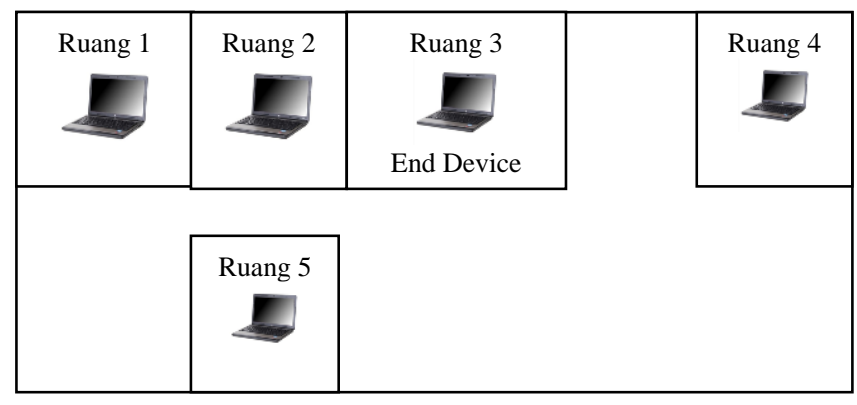

Gambar 13. Skema pengujian indoor Xbee.

\subsection{Lingkungan Indoor}

Pengujian indoor dilakukan pada lingkungan laboratorium yakni melihat kehandalan sensor dalam sebuah bangunan. Skema ruangan pada pengujian lingkungan indoor dapat dilihat pada gambar 14.

\section{a. Topologi Pair}

Pengujian topologi pair dilakukan dengan mengirimkan data dengan Xbee pengirim pada ruang 3 menggunakan dua buah modul Xbee. Kemudian Xbee penerima ditempatkan pada ruang 1 sampai 5. Adapun hasil pengujiannya dapat diliat pada Tabel 7.

Tabel 7. Hasil pengujian Xbee topologi pair.

\begin{tabular}{clc}
\hline Pengujian ke - & Ruang & Keterangan \\
\hline 1. & Ruang 1 & Terkirim \\
2. & Ruang 2 & Terkirim \\
3. & Ruang 3 & Terkirim \\
4. & Ruang 4 & Terkirim \\
5. & Ruang 5 & Terkirim \\
\hline
\end{tabular}

\section{b. Topologi Star}

Topologi star melakukan pengujian dengan tiga buah modul Xbee. Pengujian tersebut dengan cara mengirimkan data dengan Xbee pengirim berada di ruang 3. Kemudian Xbee penerima ditempatkan pada ruang 1 sampai 5. Hasil pengujian untuk topologi star dapat dilihat pada Tabel 8. 
Tabel 8. Hasil pengujian Xbee topologi star.

\begin{tabular}{cll}
\hline Pengujian ke - & Ruang & Keterangan \\
\hline 1. & Ruang 1 & Terkirim \\
2. & Ruang 2 & Terkirim \\
3. & Ruang 3 & Terkirim \\
4. & Ruang 4 & Terkirim \\
5. & Ruang 5 & Terkirim \\
\hline
\end{tabular}

c. Topologi Mesh

Pengujian pada topologi mesh menggunakan tiga buah modul Xbee. Topologi mesh mengirimkan data dengan Xbee pengirim terletak pada ruang 3, sedangkan router diletakkan diluar ruang 3. Kemudian Xbee penerima ditempatkan pada ruang 1 sampai 5. Adapun hasil pengujiannya dapat dilihat pada Tabel 9.

Tabel 9. Hasil pengujian Xbee topologi mesh.

\begin{tabular}{cll}
\hline Pengujian ke - & Ruang & Keterangan \\
\hline 1. & Ruang 1 & Terkirim \\
2. & Ruang 2 & Terkirim \\
3. & Ruang 3 & Terkirim \\
4. & Ruang 4 & Terkirim \\
5. & Ruang 5 & Terkirim \\
\hline
\end{tabular}

\section{d. Topologi Tree 1}

Pengujian pemantauan secara nirkabel pada topologi tree 1 ini dilakukan dengan lima buah modul Xbee. Pengujian dilakukan dengan mengirimkan data dengan Xbee pengirim pada ruang 3 , sedangkan router 1 dan 2 diletakkan diluar ruang 3. Kemudian Xbee penerima ditempatkan pada ruang 1 sampai 5. Sedangkan hasil pengujiannya dapat dilihat pada Tabel 10.

\begin{tabular}{cll}
\multicolumn{3}{l}{ Tabel 10. Hasil pengujian Xbee topologi tree 1. } \\
\hline Pengujian ke - & Ruang & Keterangan \\
\hline 1. & Ruang 1 & Terkirim \\
2. & Ruang 2 & Terkirim \\
3. & Ruang 3 & Terkirim \\
4. & Ruang 4 & Terkirim \\
5. & Ruang 5 & Terkirim \\
\hline
\end{tabular}

e. Topologi Tree 2

Pengujian pemantauan secara nirkabel ini dilakukan dengan lima buah modul Xbee. Pengujian dilakukan dengan mengirimkan data dengan Xbee pengirim pada ruang 3 , sedangkan router 1 diletakkan diluar ruang 3 . Kemudian Xbee penerima ditempatkan pada ruang 1 sampai 5. Hasil pengujiannya dapat dilihat pada Tabel 11.

Tabel 11. Hasil pengujian Xbee topologi tree 2.

\begin{tabular}{cll}
\hline Pengujian ke - & Ruang & Keterangan \\
\hline 1. & Ruang 1 & Terkirim \\
2. & Ruang 2 & Terkirim \\
3. & Ruang 3 & Terkirim \\
4. & Ruang 4 & Terkirim \\
5. & Ruang 5 & Terkirim \\
\hline
\end{tabular}

ISSN (e): 2540-9123

ISSN (p): 2502-1982 
f. Topologi X

Pengujian yang terakhir adalah topologi $\mathrm{x}$. Pengujian dilakukan dengan mengirimkan data dengan Xbee pengirim pada ruang 3, sedangkan router 1 dan 2 diletakkan diluar ruang 3. Kemudian Xbee penerima ditempatkan pada ruang 1 sampai 5. Adapun hasil pengujiannya dapat dilihat pada Tabel 12.

Tabel 12. Hasil topologi $\mathrm{x}$.

\begin{tabular}{cll}
\hline Pengujian ke - & Ruang & Keterangan \\
\hline 1. & Ruang 1 & Terkirim \\
2. & Ruang 2 & Terkirim \\
3. & Ruang 3 & Terkirim \\
4. & Ruang 4 & Terkirim \\
5. & Ruang 5 & Terkirim \\
\hline
\end{tabular}

\subsection{Lingkungan Outdoor}

Pengujian outdoor dilakukan untuk mengetahui jarak maksimal jangkauan yang didapat oleh Xbee. Pengujian outdoor ini dilakukan di tempat parkir Laboratorium Teknik Fakultas Teknik Universitas Jenderal Soedirman.

a. Topologi Pair

Pada topologi pair ini dilakukan pengujian dengan jangkauan jarak 30m. Gambar 14 menunjukkan skema pengujian untuk topologi pair.

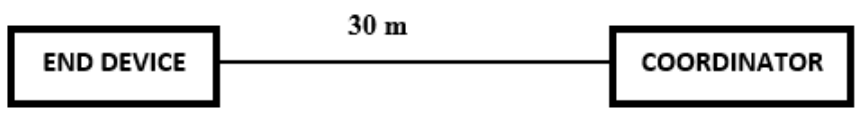

Gambar 14. Skema pengujian outdoor Xbee topologi pair.

\section{b. Topologi Star}

Sama halnya dengan topologi pair, pada topologi star ini dilakukan pengujian dengan jangkauan jarak dari end device 1 ke coordinator $15 \mathrm{~m}$ sedangkan dari end device ke coordinator $45 \mathrm{~m}$. Gambar 15 akan menunjukkan gambar skema pengujian topologi star.

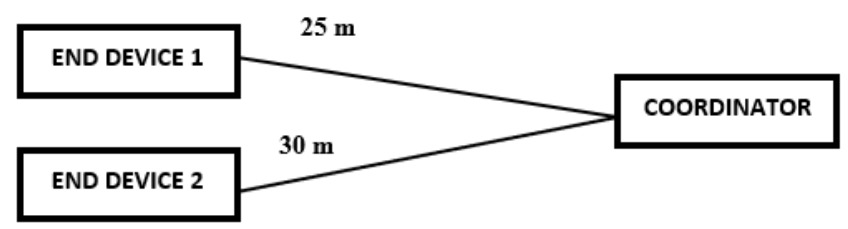

Gambar 15. Gambar skema pengujian outdoor Xbee topologi star.

\section{c. Topologi Mesh}

Dengan menggunakan router maka jangkauan Xbee akan bertambah menjadi $52 \mathrm{~m}$ karena coordinator tidak dapat menerima data dari end device tanpa melewati router. Skema pengujian topologi mesh daat dilihat pada Gambar 16.

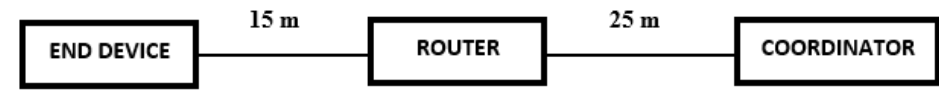

Gambar 16. Gambar skema pengujian outdoor Xbee topologi mesh.

ISSN (e): 2540-9123 
d. Topologi Tree 1

Dengan menggunakan router maka jangkauan Xbee akan bertambah menjadi $63 \mathrm{~m}$ karena coordinator tidak dapat menerima data dari end device tanpa melewati router. Skema pengujian untuk topologi tree 1 dapat dilihat pada Gambar 17.

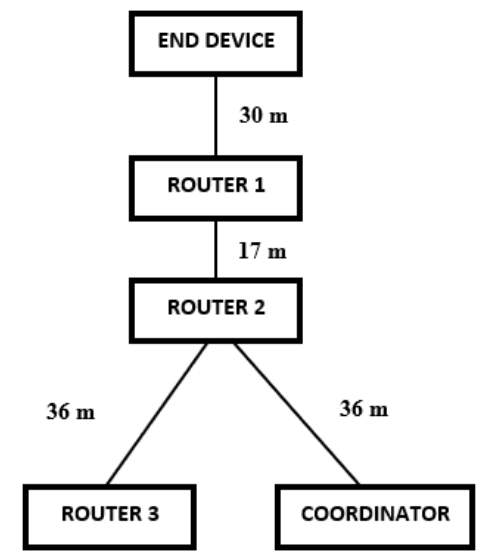

Gambar 17. Skema pengujian outdoor Xbee topologi tree 1.

e. Topologi Tree 2

Dengan menggunakan router maka jangkauan Xbee akan bertambah menjadi $60 \mathrm{~m}$ karena coordinator tidak dapat menerima data dari end device tanpa melewati router. Gambar skema pengujian untuk topologi tree 2 dapat dilihat pada Gambar 18.

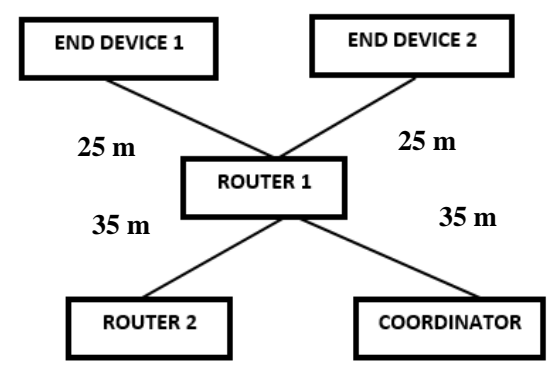

Gambar 18. Skema pengujian outdoor Xbee topologi tree 2.

\section{f. Topologi X}

Topologi $\mathrm{x}$ adalah pengujian yang memiliki jarak jangkauan paling jauh dibandingkan dengan pemodelan sebelumnya. Hal ini dikarenakan jarak dari end device melewati router 2 menuju coordinator adalah $120.5 \mathrm{~m}$ sedangkan end device melewati router 1 menuju coordinator adalah $100 \mathrm{~m}$. Skema topologi x dapat dilihat pada Gambar 19.

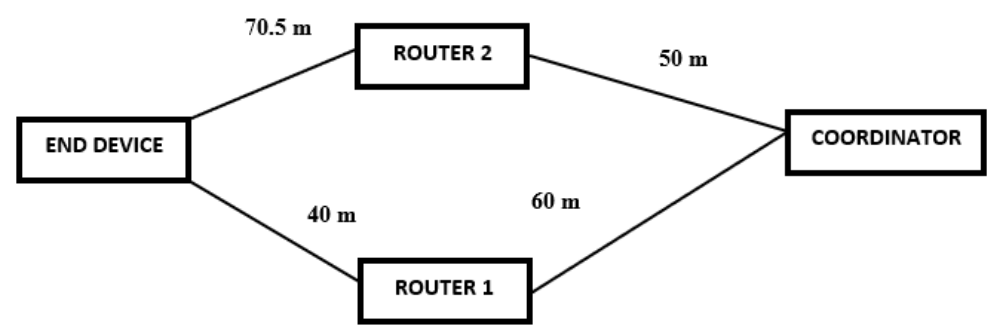

Gambar 19. Skema pengujian outdor topologi $\mathrm{x}$. 


\section{Kesimpulan}

Berdasarkan penel;itian yang telah dilakukan, topologi $\mathrm{x}$ dapat diketahui bahwa topologi $\mathrm{x}$ memiliki keamanan yang baik karena apabila salah satu router mengalami kerusakan, data akan tetap bejalan karena memiliki router pengganti dan pengujian ini memiliki jangkauan jarak yang luas di banding dengan pemodelan yang lain, namun kelemahan dari pengujian ini adalah data yang diterima oleh koordinator menjadi acak dan tidak rapih dikarenakan menerima data dari router 1 dan router 2 . Sedangkan untuk topologi tree 1 ataupun tree 2 memiliki kelebihan yaitu data yang diterima lebih rapih dari topologi $x$. Hal ini dikarenakan pada topologi jenis ini hanya menerima dari 1 data kiriman dari router. Tetapi dari tingkat keamanan kurang baik karena router yang tersedia hanya 1 , jadi ketika salah satu router mengalami kerusakan, tidak ada penggantinya.

\section{Referensi}

[1]. D.A.Putra, dan R.Mukhaiyar, "Monitoring Daya Listrik Secara Real Time", J.Voteknika, Vol. 8, No. 2, Juni 2020.

[2]. S.Silasno, dan R.Saleh, "Desain dan Implementasi Sistem Monitoring Sumber Dara Server Menggunakan Zabbix 4.0", JUITA: Jurnal Informatika e-ISSN: 2579-8901; Vol 8, No 2, November 2020.

[3]. M.Zaini, Safrudin, Dan M.Bachrudin, "Perancangan Sistem Monitoring Tegangan, Arus Dan Frekuensi Pada Pembangkit Listrik Tenaga Mikrohidro Berbasis Iot", T E S L A Vol. 22 No. 2 Oktober 2020.

[4]. H.Fauzi, Y.Yulianto dan S.Adhisuwignjo, "Sistem Monitoring Keluaran Pada Pembangkit Listrik Tenaga Mikrohidro Berbasis IOT”, ELKOLIND, Vol 7, No 1 (2020).

[5]. I.Hanggara dan H.Irvani, "Potensi Pltmh (Pembangkit Listrik Tenaga Mikro Hidro) Di Kecamatan Ngantang Kabupaten Malang Jawa Timur", Jurnal Reka Buana, Vol 2 No 2, Maret 2017 - Agustus 2017.

[6]. M.I.Munabbih, E.D.Widiantor,Y.E.Windarto, dan E.Y.Indrasto,’Rancang Bangun Sistem Pemantauan Kualitas Udara Menggunakan Arduino dan Lora Berbasis Jaringan Sensor Nirkabel", TRANSMISI, 22, (1), Januari 2020

[7]. E.Permana, dan S.Herawati, "Rancang Bangun Sistem Monitoring Suhu Ruangan Bagian Pembukuan Berbasis Web Meggunakan Mikrokontroler Arduino Uno R3”, Jurnal STMIK Subang, Vol. 11 No. 1 (2018): April.

[8]. I.N.B.Hartawan, I.G.M.N.Desnanjaya, "Analisis Kinerja Protokol Zigbee di Dalam dan di Luar Ruangan sebagai Media Komunikasi Data Pada Wireless Sensor Network", Jurnal Resistor, Vol. 1 No 2- Oktober 2018.

[9]. P.Asmaleni, D.Hamdani, dan I.Sakti, "Pengembangan Sistem Kontrol Kipas Angin dan Lampu Otomatis Berbasis Saklar Suara Menggunakan Arduino Uno", Jurnal Kumparan Fisika, Vol.3, No.1, April 2020 